\title{
Un hito de la legislación laboral estadounidense: la ley nacional de relaciones laborales o ley Wagner (1935)
}

\author{
MARÍa LUz ARROYo VÁzQUEZ
}

\begin{abstract}
RESUMEN
Durante el New Deal, la legislación laboral adquiere una especial importancia política. Este artículo aborda uno de los principales hitos legislativos sindicales en los Estados Unidos: la ley nacional de relaciones laborales o ley Wagner. Ahora bien, mientras que el título de la ley nos incita a pensar en un ámbito extenso de regulación de las relaciones entre patronos y trabajadores, ésta se limita a proteger y garantizar la libertad de sindicarse, el proceso de la negociación colectiva y el derecho a la huelga. En este ensayo se analizan los antecedentes, el desarrollo, los objetivos, y el impacto que tiene esta ley en el mundo laboral estadounidense. Finalmente, se incluye una reflexión sobre la visión que presenta la prensa española coétanea sobre esta medida.

PALABRAS CLAVES New Deal, legislación laboral, sindicalismo, negociación colectiva, derecho a la huelga.
\end{abstract}

\section{ABSTRACT}

During the New Deal, labor legislation acquires a special political importance. This article tackles one of the main legislative landmarks in the New Deal: the National Labor Relations Act. However, whereas the title of the law leads us to think of a very extended sphere in the regulation of the relationship between employers and workers, the law is limited to protecting and guaranteeing the freedom to enter a union, the process of collective bargaining and the right to go on strike. This essay analyses the background, the development, the objectives, and the impact that this law has on the American world of labor. Finally, a reflection on the vision presented by the coetaneous Spanish press upon this measure is included.

\section{KEY WORDS}

New Deal, labor legislation, sindicalism, collective bargaining, right to go on strike. 


\section{INTRODUCCIÓN}

Al comenzar la década de los años treinta, los Estados Unidos se encuentraban sumidos en una profunda crisis económica, que se extiendía al resto del mundo occidental. Las potencias europeas como Gran Bretaña y Francia estaban endeudadas con Estados Unidos y a su vez exigían el pago de las reparaciones de guerra a Alemania. Este sistema triangular hacía que la Depresión, en principio norteamericana, se extiendiese a Europa y llegase a ser considerada un fenómeno mundial.

En los tres años que precedieron la llegada de Roosevelt al poder, Estados Unidos dejaron de ser el ejemplo de «tierra prometida». En dicho país, al igual que el resto del mundo atlántico, se vivía una profunda depresión en el momento de ser elegido presidente el candidato demócrata Franklin Delano Roosevelt. Sin embargo, la sensación de desesperanza cambió cuando Roosevelt ocupó la presidencia el día 4 marzo de 1933, proyectando confianza y optimismo e impulsando la unidad nacional. Estados Unidos proyectaban una imagen de país en guerra psicológica contra la Depresión mundial. No obstante, el Presidente estadounidense en 1933, aunque estaba atento a cuestiones de política internacional, su atención quedaba canalizada hacia los problemas domésticos, porque estaba convencido de que el problema principal es la Depresión «en casa» 1.

En ese contexto crítico empiezó a funcionar el New Deal (nuevo trato), el mundo occidental permanecía atento en todo momento al desarrollo de una política nueva, democrática y distinta de la llevada a cabo por los regímenes fascistas y totalitarios. Roosevelt emprendió una política denominada New Deal bajo la mirada atenta del resto del mundo, y particularmente de los países occidentales. El término New Deal lo incluye Samuel I. Rosenman en el discurso que pronunció Franklin Delano Roosevelt ante la Convención Nacional Demócrata el 2 de julio de 1932 en Chicago, comprometiéndose a llevar a cabo una nueva política con estas palabras:

«Os comprometo, me comprometo, a un nuevo trato para el pueblo americano.

Todos los aquí reunidos constituyámonos profetas de un nuevo mandato de competencia y de coraje»? 2 .

\footnotetext{
Franklin Delano Roosevelt. "First Iriaugural Address", March 4, 1933. En: John Gabriel Hunt (ed.). The Essential FDR. New York: Gramercy Books, 1995, pág. 33.

2 Traducción de la autora. Texto original: «/ pledge you, I pledge myself, to a New Deal for the American people. Let us all here assembled constitute ourselves prophets of a new order of competence and of courage». Franklin Delano RooseVELT. «Speech before the 1932 Democratic National Convention.- A New Deal». En: John Gabriel Hunt (ed.), op. cit., pág. 29.
} 
El New Deal fue todo un símbolo, una idea potente de ámbito nacional, pero con proyección internacional. Al mismo tiempo, fue un prograrna político controvertido que tendió, especialmente durante el primer mandato presidencial, a crear nuevas leyes, tratando de responder a la demanda de soluciones a la crisis que solicitan los ciudadanos americanos.

Dicho impulso legislativo se divide por muchos autores, desde Basil Rauch, en dos períodos, el primero de 1933 a 1935 y el segundo de 1935 a $1938{ }^{3}$. El primer período se identificó con la recuperación y la ayuda social con el objetivo inmediato de aliviar los sufrimientos de algunos sectores sociales más indefensos ante la Depresión económica, tratando al mismo tiempo de aumentar los precios en la agricultura y en la industria. El segundo período del New Deal en cambio, puso mayor atención en la reforma, aumentando el poder de compra, impulsando legislación laboral, introduciendo la seguridad social y beneficiando a los pequeños comerciantes y a los trabajadores ${ }^{4}$. El segundo New Deal buscó romper los grandes monopolios y socavar el crecimiento de movimientos radicales como los de Huey Long, el padre Charles E. Coughlin y Francis E. Townsend, entre otros. Este proceso acabó en 1938. En la historiografía más reciente se distingue un tercer New Deal que empiezaba en el año 19371938 con medidas de más largo alcance.

El New Deal también se puede ver como un todo, ya que reforma y recuperación coexistieron a lo largo de todo el período. En este sentido, el historiador William E. Leuchtenburg opina que Basil Rauch y Rexford Tugwell exageran el cambio de 1933 a 1935, pues antes de 1935 se trabajó sobre muchas de la medidas que se aprobaron en ese año ${ }^{5}$. Sin embargo, Arthur M. Schlesinger, Jr. piensa que 1935 marcó un cambio en la forma de «perseguir objetivos» y «en la atmósfera». Entre los primeros New Dealers predomina la utopía y el optimismo y en los segundos el realismo ${ }^{6}$. Surgieron nuevos políticos como Corcoran y Cohen que afrontaron otros

\footnotetext{
Sobre las dos fases del New Deal véase: Basil Rauch. The History of the New Deal. New York: Creative Age Press, Inc., 1944; Arthur M. Schlesinger, Jr., The Age of Roosevelt. The Politics of Upheaval. Boston: Houghton Mifflin Co., 1960; Paul ConkIN, The New Deal. Urbana, Illinois: Harlan Davidson, Inc., 1975; James Mac Gregor Burns, James Mac Gregor Burns. Roosevelt, The Lion and the Fox. New York: Harcourt, Brace \& Co. (1956), 1984, pág. 218; Kenneth S. DavIS, FDR. The New Deal Years 1933-1937. A History. New York: Random House (1979), 1986.

${ }^{4}$ Basil Rauch, op. cit., pág. V. Esta división la siguen entre otros autores Kenneth S. Davis y Paul Conkin.

5 William E. Leuchtendung, Franklin Delano Roosevelt and the New Deal, 1932-1940. New York: Harper\& Row, Publishers, 1963, pág. 164.

${ }_{6}$ Rexford G. TugwelL, The Democratic Roosevelt. New York: Doubleday \& Co., Inc., 1957, págs. 326-7; Arthur M. SCHLESINGER, Jr., op. cit., págs. 385, 397 y 398.
} 
conflictos y nuevos objetivos. Se observa un movimiento hacia la izquierda en el segundo New Deal de carácter político. En opinión de Roosevelt, la legislación del New Deal trataba de conseguir la seguridad del ciudadano americano y, gozando de la aprobación del pueblo, buscaba no sólo introducir medidas destinadas a lograr una recuperación inmediata sino tambien una reforma ${ }^{\text {? }}$.

A la mitad de su primer mandato presidencial, Roosevelt vió amenazado y criticado su programa, por lo que surge un segundo New Deal en 1935. Cuando el 27 de mayo de 1935 se dictamina que la National Industrial Recovery Act (NIRA) (ley para la recuperación industrial nacional) no es constitucional, se puede divisar el final del primer New Deal. Así, se acometen los segundos cien días de intensa actividad legislativa entre junio y septiembre de 1935. Entre las medidas que se aprueban en esta etapa destaca la ley que abordamos en este ensayo: la ley nacional de relaciones laborales o ley Wagner.

\section{LA NATIONAL LABOR RELATIONS ACT (NLRA) O WAGNER ACT (LEY NACIONAL DE RELACIONES LABORALES O LEY WAGNER) (1935)}

\section{Antecedentes}

Durante la primera guerra mundial, el gobierno estadounidense intervino mediante medidas legislativas en las relaciones sociales e industriales. Existía una colaboración entre patronal y sindicatos y una regulación del Gobierno mediante la War Industries Board, la War Labor Policies Board y la War Labor Board. Concretamente, la War Labor Board adoptó los principios de la negociación colectiva y los trabajadores aprovecharon para sindicarse. Esto duró hasta el final de la guerra, momento en el que el gobierno dejó tal protección.

En relación a los precedentes de la legislación sindical del New Deal, se deben destacar: la Clayton anti-Trust Act (1914), la Railway Labor Act (ley de trabajadores ferroviarios) de 1926 y la Norris-La Guardia Anti-Injunction Act (ley Norris-La Guardia contra la intimidación) de 1932. El Congreso aprobó la Clayton anti-Trust Act (1914) para limitar el uso de las intimidaciones. El gobierno federal consideraba legales a los sindicatos y su derecho a existir. No obstante, en 1919 había poca disposición por

7 Franklin D. Roosevelt, «President's own story of the New Deal». Liberty, 15, March $26^{\text {th }}$, 1938, págs. 8-13, pág. 10. 
parte del patrón a llevar a cabo una negociación colectiva con el sindicato. En la década de los 20 aparecieron en su lugar los Company Favored Plant Unions (sindicatos controlados por la directiva de las empresas). Por su parte, la Railway Labor Act (ley de trabajadores ferroviarios) de 1926 requería que los patronos aceptasen los convenios colectivos y respetasen el derecho de los trabajadores a sindicarse. En 1930, el Tribunal Supremo apoyó esta ley, prohibiendo la interferencia o coacción de los patronos en la elección de representantes para la negociación colectiva en el caso Texas \& N.O.R. Co. versus Brotherhood of Railway Clerks. También en la Norris-La Guardia Anti-Injunction Act de 1932 se reconocía el derecho de los trabajadores a sindicarse, desautorizando el uso del llamado Yellowdog Contract (contrato de perro cobarde) mediante el cual el trabajador se comprometía a no unirse a un sindicato.

Durante el New Deal, encontramos el antecedente inmediato de la NLRA en la cláusula 7.a) de la ley 6/1933, National Industrial Recovery Act, NIRA (ley para la recuperación industrial nacional) que es un artículo clave de la legislación del New Deal por su repercusión en las relaciones laborales. Con él se trató de contribuir al desarrollo de los sindicatos, a proteger el derecho de los trabajadores a organizarse y a garantizar la negociación colectiva. Los trabajadores podían elegir a sus representantes en estos términos: «los empleados tienen el derecho a organizarse y negociar colectivamente a través de representantes elegidos por ellos mismos, y estarán libres de la interferencia, de los obstáculos y coerción de los patronos». ${ }^{8}$ Los sindicatos se marcaron el objetivo de negociar con la patronal para establecer las condiciones de la contratación.

Desde el principio, este artículo no aseguró «el derecho de los trabajadores a organizarse en sindicatos independientes" ${ }^{9}$. La ley interpretada a

8 Traducción de la autora. Véase: ley NIRA en US Statutes at Large. 73rd Congress, 1st Session, XLVIII (June 16, 1933), págs. 195-211, pág. 198.

(1) «That employees shall have the right to organize and bargain collectively through representatives of their own choosing, and shall be free from the interference, restraint, or coertion of employers of labor, or their agents, in the designation of such representatives or in self-organization or in other concerted activities for the purpose of collective bargaining or other mutual aid or protection; (2) that no employee and no one seeking employment shall be required as a condition of employment to join any company union or to refrain from joining, organizing, or assisting a labor organization of his own choosing; and (3) that employers shall comply with maximum hours of labor, minimum rates of pay, and other conditions of employment, approved or prescribed by the President».

9 Raymond WOLTERS, «Section 7.. and the Black Worker». En: DuBOFSKY, Melvyn (ed.). The Great Depression and the New Deal. New York: Garland Publishing, Inc., 1990, págs. 22-27, pág. 23. 
grandes rasgos contentaba a los líderes sindicales pero existía «poca resistencia institucional para evitar las evasiones sistemáticas de la ley» ${ }^{10}$. Sobre la imprecisión de este artículo de la ley NIRA, Roosevelt expresaba en una carta dirigida a Hugh Johnson su posición al respecto, comentando que el artículo garantizaba el derecho a la negociación colectiva, aunque reconocía que no hay nada en las disposiciones que interfiriera en el poder de los patronos para frenar que los trabajadores ejerciesen dicho derecho, basándose en el «mérito individual» ${ }^{11}$.

Pese a que el artículo 7.a) impulsaba la organización laboral, supuso cierta decepción pues no se respetaba, debido, en parte, a su ambigüedad y al poco deseo de los patronos de reconocer la ley. Los trabajadores no tienen plenamente garantizado el derecho al convenio colectivo con los patronos a través de sus representantes. Es decir, el artículo 7.a) en la práctica negaba la teoría. Así, ante el fracaso de una huelga textil en Carolina del Norte, los obreros que participaron en ella no fueron readmitidos en sus puestos de trabajo que fueron cubiertos durante el conflicto, anulándose así los efectos del artículo 7.a) de la NIRA ${ }^{12}$.

La junta que surgió con la ley NIRA nació como respuesta a las huelgas de finales de 1933, para fortalecer el artículo 7.a) y arreglar las disputas laborales, pero fue ineficaz en ambos objetivos. En caso de negativa a aceptar el código, el National Recovery Administration (organismo para la recuperación nacional) se vió obligado a pasar por alto la aceptación incondicional de la ley.

El aumento de los Company Unions (sindicatos controlados por la directiva de las empresas) destruía el programa, y la ambigüedad de la ley llevaba a tal ausencia de poder que hacía que los patronos no sigiesen la ley. En 1935 hay 2'5 millones de trabajadores bajo estos planes frente a

10 Stanley Vitroz, New Deal Labor Policy and American Industrial Econmy. London: The University of North Carolina Press, 1987, pág. 138.

11 Carta de Franklin Delano Roosevelt a Hugh Johnson. October 19th, 1934. Franklin Delano Roosevelt's Personal File. Franklin Delano Roosevelt Library, Hyde Park (New York).

« $\mathrm{B}$ cause it is evident that the insertion of any interpretation of Section 7(a) in a Code of Fair Comp tition leads only to further controversy and confusion, no such interpretation should be incorpo:ated in any Code. While there is nothing in the provisions of Section 7(a) to interfere with bona fide exercice of the right of an employer to select, retain or advance employees on the basis of individual merit, Section 7(a) does cleariy prohibit the pretended exercice of this right by an employer simply as a device for compelling employees to refrain from exercising the rights of selforganization, designation of representatives and collective bargaining, which are guaranteed to all employees in said Section $7(a) »$.

12 José Escuder, «Ocaso de la democracia en los Estados Unidos». Leviatán (Madrid), junio 1935, n. ${ }^{\circ} 14$, pág. 29. 
4'1 millones de miembros de sindicatos obreros, pues las empresas o bien ignoraban esta ley o reactivaban planes de representación de empleados y sindicatos controlados por las directivas de las distintas empresas ${ }^{13}$. Existía un problema con el término, con el significado de la negociación colectiva, a través de representantes elegidos por los propios trabajadores. De este modo, pese a que líderes sindicales como John Lewis insistían en que Roosevelt quería que los obreros se unieran a los trabajadores independientes, muchos hombres de negocios se dieron cuenta de que la legislación no especificaba la manera en la que los representantes debían ser elegidos y buscaron cumplir con los términos del artículo 7.a), estableciendo sindicatos controlados por las empresas ${ }^{14}$.

Algunos autores consideran que el artículo 7.a) fue el punto de partida del renacimiento sindical, pues reconocía la libertad sindical y el derecho de los trabajadores a elegir sus representantes al tiempo que amenazaba a los sindicatos de empresa al permitir que los representantes libremente elegidos negociasen convenios colectivos. Según Foster Rhea Dulles, a raíz de la aprobación del artículo 7.a), estalló «una actividad sindical que no tenía precedente excepto quizás en el crecimiento de los Knights of Labor medio siglo antes» ${ }^{15}$. El historiador coétaneo de izquierda George E. Sololsky sugiere que el artículo 7.a) permitió que la $A F L$ pudiese fortalecer su dominio, convirtiéndose en un gran sindicato ${ }^{16}$. Sean Dennis Cashman, en cambio, opina que tuvo un «efecto simbólico» el hecho de que el gobierno federal legitimase el derecho de los trabajadores a sindicarse, es decir, un efecto galvanizador y no efectivo ${ }^{17}$. No parece haber una gran libertad en la práctica, aunque el artículo 7.a) induciese a la acción de sindicato y empresa bajo la supervisión gubernamental. Por su parte, Rhonda F. Levine afirma que el artículo 7.a) intensificaba «la lucha de clases entre el capital industrial y el trabajo industrial» ${ }^{18}$. Además, esta

\footnotetext{
13 Sean Dennis Cashman, America in the Twenties and Thirties. The Olympian Age of FDR. New York: New York University Press, 1989, págs. 231-232.

14 Raymond WOLTERS, op. cit., pág. 23.

15 Foster Rhea Dulles, Labor in America. A History. New York: Thomas \& Crowel Co., 1949, pág. 268.

- The Noble Order of the Knights of Labor era un pequeño sindicato local de los trabajadores de corte y confección de Filadelfia. Lo fundó Uriah S. Stephens en 1869. El número de miembros creció rápidamente, pasando de 10.000 en 1879 a 700.000 en 1886 . Después del nacimiento de la $A F L$, este sindicato perdió afiliados, sobre todo, debido a disputas internas. En 1890 tenía sólo 100.000 miembros. Existió hasta 1917. Véase: US Department of Labor, 1976, págs. 10-12.

16 George E. Sololsky. Labor's Fight for Power. New York: Doubleday, Doran and Company, Inc., 1934, pág. 88.

17 Sean DenNIS CASHMAN, op. cit., pág. 232.

18 Rhonda F. LEVINE, Class Struggle and the New Deal. Industrial Labor, Industrial Capital and the State. Kansas: University Press of Kansas, 1988, pág. 109.
} 
autora manifiesta que importantes segmentos de la clase trabajadora vieron que el artículo 7.a) proporcionaba «los mecanismos legales para el reconocimiento sindical y asi forzar al capital industrial a facilitar mejores condiciones de empleo. Los capitalistas, sin embargo, se oponen sistemáticamente al artículo $7 a . . .{ }^{19}$. En pocas palabras, el artículo no se respetaba, porque se podía incumplir.

El fallo principal radicaba en que el artículo garantizaba el derecho a la negociación colectiva con los patronos, a través de representantes elegidos por los trabajadores de manera libre. Esto dejaba el camino libre para crear sindicatos controlados por los patronos de los distintos ramos de la industria, no por el sindicato obrero.

En síntesis, el artículo 7.a) expresaba las condiciones de la negociación colectiva, pero no puso los métodos para garantizarla. Era un símbolo sin resultados prácticos, que expresaba algunos principios sobre la conveniencia de que los trabajadores se organizasen, pero que no obligaba a los patronos a negociar y no preveía medio alguno para hacerlo. Además las disposiciones resultaban ambiguas y, en consecuencia, fáciles de evadir 20 .

A pesar de suponer un fracaso por no ser respetado por la patronal, este artículo tiene una importante influencia posterior, siendo rescatado en 1935 por el senador Wagner en su ley National Labor Relations Act, NLRA (ley nacional de relaciones laborales), que intentó fortalecer los sindicáos y, más tarde, influyó en la Fair Labor Standards Act (ley para unos niveles laborales justos) de 1938.

\section{Gestación de la ley}

La National Labor Relations Act (NLRA) de 1935 es una ley de carácter sindical que estableció un método práctico de llegar a acuerdos laborales, protegiendo el derecho de los trabajadores a formar parte de los sindicatos y designar a sus representantes. Fue un recurso legal de los tra-

19 Ibidem.

20 Véase estas ideas en: Irving Berstein, The New deal Collective Bargaining Policy. Berkeley: University of California Press, 1950, pág. 39; Arthur M. SCHLESINGER, Jr., op. cit., pág. 131; Sean Dennis Cashman, op. cit., pág. 232; Paul K. EdwaRds, El conflicto en el trabajo. Un análisis materialista de las relaciones laborales de empresa. Madrid: Ministerio de Trabajo y Seguridad Social, 1990, pág. 164.

- Léase también: «La muerte de la NRA». Leviatán (Madrid), junio 1935, n. ${ }^{\circ}$ 14, pág. 47. 
bajadores contra los patronos que se oponían a la sindicación y a la negociación colectiva ${ }^{21}$.

Esta ley también recibe el nombre de su creador, el senador liberal de Nueva York Robert F. Wagner ${ }^{22}$. Su biógrafo destacó el papel clave que desempeñó en la elaboración de la leyes del New Deal y se mostró de acuerdo con lo que dijo un periodista una vez, al escribir que Robert Wagner «había colocado en los libros una legislación más importante y de más alcance que ningún otro americano en la historia, desde los días de los fundadores" ${ }^{23}$. Robert F. Wagner, que participó en la elaboración de la NIRA e insistió en la inclusión del artículo 7.a), viendo la necesidad de nueva legislación, retomó la propuesta vertida en el citado artículo para diseñar un plan de relaciones laborales que garantizase el derecho a sindicarse y a la negociación colectiva.

Mediante dicho proyecto, el senador trató no sólo de conseguir devolver la armonía al lugar de trabajo tras tantas huelgas, sino también de impulsar la economía, porque él creía que la sindicación provocaba un crecimiento de los salarios, lo cual contribuía a aumentar el poder de compra. Wagner, presidente de la National Labor Relations Board, NLRB (junta nacional de relaciones laborales), dependiente del organismo $N R A$, advirtió a Roosevelt de que el problema central que provocaba los conflictos laborales era la negativa de los patronos a negociar y su interferencia en las actividades organizativas de los sindicatos ${ }^{24}$. En diciembre de 1933, Wagner comunicó a la prensa la necesidad de clarificar, reafirmar y fortalecer el artículo 7.a) de la NIRA mediante una enmienda y a final de mes, Leon Keyserling, su ayudante, se puso a trabajar en el proyecto Labor Disputes, que se presentó en el Senado el uno de marzo de 1934.

El proyecto de 1934 propuso crear una National Labor Board (junta nacional laboral) permanente armada con poderes de citación y autoridad para ejecutar órdenes directamente en los tribunales de distrito federales. Dicha medida no fue bien acogida ni por el gobierno Roosevelt ni por la patronal. Según J. Joseph Huthmacher, «aunque Wagner insistió en que su proyecto fue diseñado para promover la cooperación entre los trabaja-

21 Frances Perkins, «The Social Security Act». Speech delivered over Columbia Broadcsting System, September 2, 1935. Vital Speeches. Vol. I, n. ${ }^{\circ}$ 25, September 9, 1935, pág. 794; Frances PERKINS, Informe al Presidente Roosevelt. Dec. 31, 1943, pág. 28.

22 Robert FERDINAND WAGNER (1877-1953) fue senador del Estado de Nueva York de 1927 a 1949 y promovió leyes importantes, entre las que destaca la NLRA.

${ }_{23}$ J. Joseph HUTHMACHER, Senator Robert F. Wagner and the Rise of Urban Liberalism. New York: Atheneum, 1968, preface VIII.

24 Paul K. EDwards, op. cit., pág. 164. 
dores y la patronal, fomentando así la recuperación económica y la paz industrial, su recepción fue todo menos tranquila» ${ }^{25}$. En contra del proyecto de ley estaban la patronal, la Cámara de Comercio estadounidense, la Asociación de Fabricantes y el instituto del Hierro y del Acero. También se oponía el partido comunista, pero por diferentes motivos. A favor figuran líderes laborales como William Green y John Lewis y expertos laborales como William E. Leiserson.

Respecto al Gobierno, sólo Lloyd K. Garrison y Francis Biddle hablaron a favor de la ley Wagner, pero, aparte de ellos y algunos empleados de la existente $N L R B$, el único miembro oficial del gobierno que apareció en las vistas fue Frances Perkins, porque está interesada en asegurar una enmienda que acogiese la junta en su ministerio. Los comentarios de la Secretaria de Trabajo, según J. Joseph Huthmacher, fueron «poco entusiastas y ambivalentes» ${ }^{26}$.

Por su parte, Roosevelt continúa manteniendo su actitud paternalista frente a los obreros, procurando que ellos no sean autosuficientes, mostrando poco interés por los asuntos laborales y por conceder a los trabajadores el derecho a sindicarse ${ }^{27}$. Según Paul K. Edwards, Roosevelt no buscaba la reforma laboral, sino que aceptó las leyes laborales para conseguir la recuperación económica, y se interesó más por «una reforma social general y las demandas del trabajador individual que los derechos de los sindicatos» 28.

En cuanto a las asociaciones representantes de los trabajadores negros, la National Association for the Advancement of Colored People (NAACP) (Asociación Nacional para el avance de la Gente de Color) y la Urban League (Liga Urbana) solicitaron que en el proyecto se incluyese un artículo que prohibiese la discriminación racial por parte de los sindicatos. La $A F L$ se opuso a que dicha cláusula modificase el proyecto de ley Wagner de 1934, pues mantuvo que esa cláusula podía poner en peligro el poder de negociación con el patrón e impedir el progreso de los sindicatos. Así pues, la enmienda propuesta no se incluyó en la ley. La AFL tenía más poder que la NAACP y la Urban League. Según decía Clark Foreman en 1933, «el poder laboral residía en la AFL y en los industriales: a

\footnotetext{
J. Joseph HuTHMAcheR, op. cit., pág. 164.

Ibidem, pág. 192.

William E. Leuchtenburg, op. cit., pág. 107; Paul K. Edwards, op, cit, pág. 164; Robert S. Mac Elvaine. The Great Depression of America, 1929-1941. New York: Times Books, 1993 (1. edición en 1947), pág. 258.

28 Paul K. EDwARDS, op. cit., pág. 165.
} 
los industriales les interesaba el negro como mano de obra barata y la AFL quería eliminar la mano de obra competitiva» ${ }^{29}$.

A pesar de todo, este proyecto de ley fue rechazado, al igual que ocurrió con otros proyectos de reforma. Esto provocó cierto grado de decepción en Wagner y sus aliados ${ }^{30}$. Roosevelt bloqueó su aprobación en 1934, decidió posponerla ante las protestas que surgieron en torno a ella. Los patronos, sobre todo, fueron poco conciliadores, enviando numerosos telegramas de protesta a la Casa Blanca. Roosevelt necesitaba el apoyo de los industriales, y por ello, normalmente, se sometió a sus deseos al abordar conflictos en las relaciones entre obreros y patronos ${ }^{31}$. George $\mathrm{E}$. Sololsky, especialista en relaciones laborales y coetáneo del proyecto de ley, manifiestó que el fracaso del proyecto de ley Wagner eliminaba la posibilidad de lograr que los trabajadores estadounidenses formasen parte de un gran sindicato autorizado por el Gobierno ${ }^{32}$.

El comité de asuntos laborales del Senado elaboró un informe favorable sobre el proyecto de ley Wagner - presentado a petición de miembros como su Presidente, Wagner y Leon Keyserling - que decepcionó a la Secretaria de Trabajo, Frances Perkins, porque quería que la junta funcione como un organismo regulador independiente ${ }^{33}$.

Durante el otoño e invierno de 1934, Leon Keyserling ayudado por abogados laborales, escribió un nuevo borrador de la medida. A finales de 1934 se podían distinguir dos foros reformistas de debate y diseño de la ley: uno en Washington coordinado por Leon Keyserling, y dirigido por el senador Robert F. Wagner y otro en Nueva York, donde el Twenty Century Fund de Edward A. Filene había reunido a numerosos especialistas en cuestiones laborales, economistas, patronos progresistas y científicos sociales para dirimir el papel del gobierno en las relaciones laborales. El primer grupo daba prioridad al fortalecimiento de los derechos individuales, mientras que el segundo abogaba por los intereses de grupo, defendiendo la sindicación y la negociación colectiva, pero también la promoción de la paz industrial ${ }^{34}$.

29 Raymond WOLTERS, op. cit., pág. 37.

30 J. Joseph HUTHMACHER, op. cit., pág. 171.

31 Melvyn DuBofsky (ed.), American Labor since the New Deal. Chicago: Quadrangle Books, 1971 , págs. 6 y 7.

32 George E. SOLOLSKY, op. cit., pág. 70.

33 J. Joseph HuTHMACHER, op. cit., pág. 192.

34 Christopher L. TOMLIMS. "The New Deal, Collective Bargaining, and the Triumph of industrial Pluralism". En: DuBOFSKY, Melvyn (ed.). The New Deal. Conflicting Interpretations and Shifting Perspectives, 1992, págs. 305-331, págs. 315-316. 
El nuevo diseño de la ley se hizo de forma cuidadosa, procediendo sin consultar a la Secretaria de Trabajo y con independencia respecto de la sanción de la Casa Blanca en vista de las reticencias ya mostradas por el Presidente para aceptarla ${ }^{35}$. Sin embargo, eso no impidió que se manifestasen temores de que, tras la decisión del Tribunal Supremo de declarar la NRA inconstitucional, la ley Wagner pudiese correr la misma suerte. Por ello, hubo miembros del Gobierno que pidieron al Presidente Roosevelt que informase sobre la constitucionalidad de la ley para tranquilizar a la opinión pública ${ }^{36}$. Daniel C. Roper, ministro de Comercio, insistió en una carta dirigida al Presidente Roosevelt en que se enmendase el proyecto de ley antes de ser firmado y se incluyese una disposición que garantizase a los trabajadores protección ante cualquier tipo de intimidación y coacción ${ }^{37}$.

El proyecto de ley de 1935 era similar al de 1934 en cuanto a los derechos que especificaba y a la lista de prácticas que se prohibían a la patronal y difería del de 1934 en que ponía de relieve la posición de la NLRB como tribunal supremo de las relaciones laborales, enfatizando la aplicación de los derechos laborales más que el ajuste de diferencias. Todos los miembros de la junta debían representar al público, rechazando así la primera propuesta de crear un grupo tripartito con representación de los patronos, los trabajadores y los consumidores. Estos cambios no afectaban a los trabajadores negros, que incluso criticaron el proyecto de $1934{ }^{38}$.

El Presidente se mostraba cauteloso en el invierno de 1934 y en la primavera de 1935. También Frances Perkins parecía ambivalente a la hora de respaldar el proyecto. Para J. Joseph Huthmacher, «la principal preocupación de Frances Perkins parecía ser que la nueva junta estuviese localizada dentro del dominio de su Departamento de Trabajo antes de que disfrutara de un estatus independiente" ${ }^{39}$. La versión de Huthmacher se contradice con la de Frances Perkins. Ésta última suponía que la experiencia del Ministerio de Trabajo contribuía a que al senador Wagner, Chairman of the Mediator Board (director de la junta mediadora), que es-

\footnotetext{
35 Irving BERSTEIN, op. cit., pág. 84; William E. LEUCHTENBURG, op. cit., pág. 111; J. Joseph HuthMACHeR, op. cit., pág. 190.

36 Véase carta de Daniel C. Roper, Secretario de Comercio, a Roosevelt sobre la constitucionalidad de la Wagner Labor Disputes Bill. June 20th, 1935. Folder 407. Franklin Delano Roosevelt Library. Hyde Park, New York.

${ }_{37}$ Véase carta de Daniel C. Roper, Secretario de Comercio a F.D.R. sobre la Wagner Labor Bill. Folder 407. Franklin Delano Roosevelt Library. Hyde Park, New York.

38 Raymond WOLTEAS, op. cit., pág. 1934.

39 J. Joseph Huthmacher, op. cit, pág. 166.
} 
taba muy interesado por los asuntos laborales, elaborase esta ley. Asimismo, la Secretaria comentaba que el Ministerio de Trabajo había previsto que negar a los trabajadores su derecho a sindicarse conduciría a huelgas y dificultaría el comercio interestatal ${ }^{40}$.

Una vez diseñado el nuevo proyecto de ley, que, en realidad, apenas se diferenciaba del de 1934, Wagner volvió a proponerlo en 1935, en una situación muy distinta a la del año anterior. Así, por ejemplo, los cambios electorales de 1934 influyeron de manera decisiva en la legislación laboral. Además, se argumenta después que la militancia obrera y la respuesta política a la oleada creciente de huelgas de 1934 allanaron el camino para la aprobación de la ley Wagner. El columnista Walter Lippmann publicó que cuando el movimiento obrero se hizo fuerte, arraigó la ley ${ }^{41}$.

Wagner pensaba que el artículo 7.a) no podía dejarse languidecer y reclamó a la Cámara de Representantes que apoyase la NLRA. Esta ley constituía, en su opinión, "la única llave al problema de estabilidad económica si tratamos de confiar en la propia ayuda democrática mediante la industria y el trabajo, en lugar de exponerse a los peligros de un estado arbitrario o totalitario» ${ }^{42}$.

El proyecto fue llevado al Senado, donde se aprobó el 16 de mayo de 1935 por un amplio margen, 63 votos a favor y 12 votos en contra (de 8 republicanos y 4 demócratas conservadores). Roosevelt, viendo que la ley sería aprobada por la Cámara de Representantes, decidió apoyarla. La Cámara de Representantes la sancionó, por 200 votos contra 1, el día 27 de junio ${ }^{43}$. En síntesis, las Cámaras ordenaron a los patronos que dejasen de resistirse a la expansión de los sindicatos y se ayudase a los trabajadores a que pudiesen elegir libremente si querían o no pertenecer a un sindicato.

Roosevelt dijo el día 24 de mayo que aprobaría la $N L R A$, antes de que fuera anunciada la invalidación de la NIRA y la -firmó de hecho el 5 de julio, comunicándoselo seguidamente a Wagner ${ }^{44}$. No obstante, según Arthur M. Schlesinger, ni el Gobierno ni Roosevelt se sintieron entusias-

\footnotetext{
40 Frances Perkins, «Report to the President on Ten Years' Achievements in Labor and Social Improvements». December 31, 1943, págs. 28-29. pág. 146.

42 J. Joseph Huthmacher, op. cit., pág. 195

43 William E. LeUCHTENBURG, op. cit., pág. 152.

44 Sobre el comunicado de la aprobación de la ley Wagner por Roosevelt, véase el telegrama que le envía M.H. Mac Intyre a Wagner. July 5th, 1935.
} 
mados con esta medida ${ }^{45}$. Roosevelt parecía no darse cuenta de que el problema era si los obreros podían, o no, seguir estando representados por sindicatos de empresa y por una gran variedad de portavoces minoritarios cuya desunión sólo debilitaba a los obreros ${ }^{46}$. Ni el Presidente, ni Johnson, ni Richberg, ni Frances Perkins secundaron la NLRA eficazmente. ${ }^{47}$ Roosevelt la apoyó muy tarde. Quizá inició una línea más reformista al respaldar la ley para ganar el favor de los trabajadores y sindicatos en las elecciones presidenciales de $1936^{48}$. La respuesta de los líderes liberales y de los patronos fue parecida a la que tuvieron anteriormente: los primeros ampararon la ley y los segundos fueron reacios a aceptarla 49 .

En cuanto a la actitud del Tribunal Supremo respecto a la ley Wagner, observamos que no fue declarada anticonstitucional como la NIRA. El Tribunal Supremo apoyó la ley el 12 de abril de 1937 en el caso National Labor Relations Board versus Jones and Laughlin Steel Company por 5 votos contra 4.

\section{Objetivos y principales disposiciones de la ley}

La Wagner Act trató de regular las relaciones entre empresarios y sindicatos, centrándose en la lucha de los trabajadores por el derecho a sindicarse y por el convenio colectivo. Los objetivos de la ley se indican en el preámbulo de la misma: «para disminuir las causas de los conflictos laborales que agobian u obstruyen el comercio interestatal y extranjero, para crear una Junta de Relaciones Laborales, y para otros motivos» ${ }^{50}$. Se buscó la negociación colectiva como la mejor vía para reducir el nivel del conflicto laboral en general y de las huelgas en particular ${ }^{51}$. En el informe elaborado por el comité de asuntos laborales del Senado, Robert Wagner y Leon Keyserling ponían de relieve dos objetivos fundamentales de la ley: «eliminar el primer motivo de huelgas, haciendo más seguro el derecho de los trabajadores a organizarse, y mejorar el ciclo de los negocios restaurando un mejor

45 Arthur M. SCHLEsINGer, The Age of Roosevelt. the Coming of the New Deal. New York: The American Heritage Library (1958), 1988, pág. 401.

46 James Mac Gregor Burns, Roosevelt, op. cit, pág. 218.

47 William E. LeuChtenBurg, op. cit., pág. 151.

48 Charles O. Gregory \& Harold A. KaTz. Labor and Law. New York: W.W. Norton \& Company, 1979, pág. 225; Robert S. Mac Elvaine, op. cit., pág. 258.

49 J. Joseph Huthmacher, op. cit., pág. 191.

so US Statutes at Large, 74th Congress, 1st Session, Chapter 372, vol. XLIX, part 1, July 5, 1935, pág. 449

51 lbidem. 
equilibrio entre la producción y el consumo a través de un aumento en los salarios, que sólo una negociación colectiva podría traer» ${ }^{52}$.

El senador Wagner insistía en que había diseñado esta ley para beneficiar al país en general, a patronos y trabajadores, con el propósito de upromover la paz, el tipo de paz equitativa que descansa en la libertad, no en las trabas; en la igualdad, no en el servilismo; en la cooperación, no en la dominación» ${ }^{53}$. Resulta interesante observar que los objetivos de Wagner parecen distintos a los de Hugh Johnson o Roosevelt. Mientras que éstos hacían hincapié en conseguir empleo a los parados, Wagner deseaba además que se respetasen y se cumpliesen los derechos de los trabajadores ${ }^{54}$.

Según Foster Rhea Dulles, «por primera vez un gobierno nacional en Estados Unidos iba a hacer del bienestar de los trabajadores industriales una preocupación directa del gobierno y actuar bajo el principio de que sólo los obreros sindicados podían tratar en los mismos términos con el capital organizado» ${ }^{55}$. Este historiador baraja dos ideas muy distintas. Por un lado, el ensanche de competencia del gobierno federal, que mostraba un interés por proteger el bienestar obrero $y$, por otro lado, el hecho de que sólo los sindicatos podían negociar con el capital. Esta suposición, puede entenderse como apoyo al principio de solidaridad y organización obreras y, como crítica de no atender a obreros no sindicados.

En cuanto al contenido de la ley, la National Labor Relations Act (o Wagner Act) consta de dieciséis artículos, pudiéndose destacar las disposiciones siguientes:

En el artículo primero: Findings and Policy (hallazgos y política) se expresa que la ley intenta animar a la negociación colectiva y proteger el derecho de asociación de los trabajadores. También expone que la negativa patronal a aceptar la negociación colectiva provoca problemas huelguísticos y pone trabas al buen funcionamiento del comercio. Asimismo, en él se comenta que existe una desigualdad entre la patronal y los empleados a la hora de entablar la negociación colectiva, lo cual desestabiliza la industria. Por ello, se declara la política a seguir:

«Eliminar las causas de ciertos obstáculos serios al libre movimiento del comercio, y mitigar y suprimir estas dificultades cuando hayan ocurrido, al animar y proceder con la negociación colectiva mediante la protección del

52 J. Joseph Huthmacher, op. cit., pág. 192.

53 Ibidem, pág. 193.

54 Ibidem, pág. 191.

55 Foster RHEA DuLLES, op. cit., págs. 264-265. 
ejercicio por los trabajadores del pleno derecho de asociación, organización autónoma, y designación de representantes de su propia elección, con el propósito de negociar los términos y condiciones de su contratación u otra ayuda o protección solidarias ${ }^{56}$.

La insistencia en que todo se hacía para quitar obstáculos al comercio es porque sólo así se podía justificar la intervención federal. La Constitución la autorizaba para el comercio y relaciones inter-estatales, pero el Gobierno no podía interferir en asuntos internos de los Estados sin más.

En el artículo segundo: Definitions (definiciones) se aclara el significado de los términos claves utilizados en la ley.

Los artículos tercero, cuarto, quinto y sexto tratan sobre la National Labor Relations Board (junta nacional de relaciones laborales). Mediante el artículo tercero se crea la junta nacional de relaciones laborales y se explica que constará de tres miembros designados por el Presidente con el consejo y consentimiento del Senado. Igualmente, se anuncia la duración de dichos cargos, la elección de un presidente de la junta, se determina el número de asistentes a la junta para que exista quorum y se programa la elaboración de un informe anual.

Los artículos séptimo y octavo abordan los derechos de los empleados. El artículo séptimo es uno de los más importantes de la ley ya que especifica los derechos de los trabajadores. Dice así: «los trabajadores tendrán el derecho a organizarse ellos mismos, formar, unirse o tomar parte en organizaciones sindicales, para negociar colectivamente a través de representantes de su propia elección u otra ayuda o protección mutua» ${ }^{57}$. El artículo octavo trata de lo que la ley considera prácticas laborales injustas por parte del patrono, destacando sobre todo, los puntos uno, dos, cuatro y cinco. En el primer punto se prohibe de forma explícita

56 US Statutes at Large, 74th Congress, 1st Session, chapter 372, vol. XLIX, part 1, July 5, 1935, págs. 449 y 450.

Texto original: «It is hereby declared to be the policy of the United States to eliminate the causes of certain substantial obstructions to the free flow of commerce and to mitigate and eliminate these obstructions when they have occurred, by encouraging the practice and procedure of collective bargaining and by protecting the exercice by workers of full freedom of association, self-organization, and designation of represeniatives of their own choosing, for the purpose of negociating the terms and conditions of their employment or mutual aid or protection".

57 US Statutes at Large, 74th Congress, 1st Session, chapter 372, vol. XLIX, part 1, July 5, 1935, pág. 452.

Texto original. Sec. 7.: «Employees shall have the right to selt-organization, to form, join, or assist labor organizations, to bargain collectively through representatives of their own choosing, and to engage in concerted activities, for the purpose of collective bargaining or other mutual aid or protection's. 
la interferencia de todo patrono en el derecho del trabajador a sindicarse: 1) «Será una práctica laboral injusta que un patrón interfiera con los empleados, los refrene, o los coaccione en el ejercicio de los derechos garantizados en el artículo $7 \%$. Mediante el punto segundo se pretende impedir la creación de sindicatos de la compañía, considerándose una práctica laboral ilícita para el patrono: «dominar o interferir con la formación o dirección de cualquier organización laboral o contribuir de manera financiera u otra para apoyarla». Los apartados cuatro y cinco del artículo citado también son importantes, porque reafirman la libertad de los trabajadores y su derecho a la negociación colectiva, prohibiendo a los patronos en el apartado cuarto "echar o discriminar de alguna forma contra un empleado porque haya presentado cargos o dado testimonio bajo esta ley» $y$ en el cinco se incide en que el patrono no puede «negarse a negociar colectivamente con los representantes de los empleados, sujeto a las disposiciones del artículo 9 a) $\gg 58$.

El artículo noveno: Representatives and Elections (representantes y elecciones) explica que los representantes de los trabajadores para la negociación colectiva se designarían por mayoría. Es decir, el sindicato que recibiese la mayoría de los votos se convertiría en el único representante que ejercería el derecho negociador para todos los empleados dentro de cada unidad negociadora.

Por su parte, el artículo décimo: Prevention of Unfair Labor Practices (prohibición de prácticas laborales injustas) trata de los poderes que se otorgan a la junta nacional de relaciones laborales para impedir que nadie lleve a cabo una práctica laboral ilícita, afectando el comercio.

Los artículos undécimo y duodécimo llevan el título de: Investigatory Powers (poderes investigadores). El artículo undécimo aborda las facultades que tiene la junta de relaciones laborales para llevar a cabo investigaciones, teniendo potestad de obtener pruebas, tomar juramento y hacer declarar a testigos.

58 lbidem, págs. 452 y 453.

Sec. 8.: «It shall be an unfair labor practice for an employer-

1) To interfere with, restrain, or coerce employees in the exercise of the rights guaranteed en section $7 \%$.

2) To dominate or interfere with the formation or administration of any labor organization or contribute financial or other to support it....

4) To discharge or otherwise discriminate against an employee because he has filed charges or given testimony under this Act.

5) To refuse to bargain collectively with the representatives of his employees, subject to the provisions of Section 9 a)". 
El artículo duodécimo especifica la pena de prisión o la multa que tendrán que pagar aquellos que interfieran y traten de impedir la actuación de cualquier miembro de la junta o de sus agentes.

También los artículos décimotercero, décimocuarto, décimoquinto y décimosexto: Limitations (prescripciones) resultan ser significativos. El artículo décimotercero es muy importante para los trabajadores, porque en él se expone que nada en esta ley debe ser interpretado para que se impida o disminuya el derecho a la huelga. El artículo décimocuarto trata de los conflictos legislativos, entre esta ley y otras, diciendo que esta ley debe prevalecer con tal de que en cualquier situación en la que las disposiciones de la ley no pudiesen ser válidamente impuestas, las cláusulas de las otras leyes mencionadas tendrían efecto. El artículo décimoquinto es una cláusula de compartimentación que intenta proteger la ley, diciendo que si una disposición fuese considerada nula, esto no afectaría al resto de la ley.

Por último, el artículo décimosexto expresa que esta ley puede ser citada como National Labor Relations Act (ley nacional de relaciones laborales) ${ }^{59}$.

\section{LA «NATIONAL LABOR RELATIONS BOARD» (JUNTA NACIONAL DE RELACIONES LABORALES)}

En el artículo tercero de la NLRA ley se especifica que la ley crea un organismo: el National Labor Relations Board (junta de relaciones laborales) ${ }^{60}$. El antecedente de este organismo era la junta de relaciones laborales de 1934, dirigida por Wagner, que fracasó al encontrarse con la resistencia patronal ${ }^{61}$. No obstante, la junta de 1935 era más fuerte que su predecesora y presentaba algunos cambios con respecto a la propuesta en 1934. Los miembros de la junta eran miembros públicos y no como se sugirió antes: un representante trabajador, otro del público y otro de la patronal. También se abandonó la obligación de la junta a comprometerse en la mediación y conciliación en conflictos laborales, quedando como un tribunal de relaciones laborales que se centró en el respeto a los derechos de los trabajadores ${ }^{62}$. La antigua junta, es decir, la establecida el 29 de

59 La ley completa véase en: US Statutes at Large, 74th Congress, 1 st Session, Chapter 372 , vol. XLIX part 1, July 5, 1935, págs. 449-457.

60 US Statutes at Large, 74th Congress, 1 st Session, chapter 372, vol. XLIX part 1, July 5 , 1935, págs. 451-452.

61 J. Joseph Huthmacher, op. cit, pág. 190.

62 Ibidem, 1968, pág. 191. 
junio de 1934 quedó abolida por la ley de 1935 y su personal pasó a formar parte de la junta creada por la ley Wagner.

Respecto a la composición de la junta, ésta constaría con tres miembros elegidos por el Presidente con el asesoramiento y consentimiento del Senado. La duración del cargo variaba. En el caso de los miembros originales, uno de ellos sería elegido por el período de un año, otro de ellos por tres años y el otro por cinco años, pero sus respectivos sucesores podían ocupar el cargo durante cinco años, excepto en caso de ocupar una vacante por el período que quedase por cumplir. El Presidente designaría presidente de la junta a uno de sus miembros. Los miembros podrían ser destituidos de su cargo por el Presidente, pero sólo en el caso de que descuidasen su cargo o cometiesen un hecho delictivo durante el desempeño del mismo. Con respecto al quorum, se consideraba que dos miembros ya lo constituían.

En relación al salario de los miembros de la junta, en la ley se estipula que recibirían la cantidad de diez mil dólares anuales, no permitiéndoseles desempeñar ningún otro cargo. Asimismo, la junta escogería el personal necesario para realizar las tareas y obligaciones de la junta tales como un secretario ejecutivo, abogados, directores regionales, pero no podría nombrar mediadores o personas, que realizasen un trabajo de tipo estadístico, puesto que esa es una tarea propia del Ministerio de Trabajo.

En cuanto a las funciones de la junta, la tarea principal consistía en impedir que los empresarios realizasen prácticas laborales injustas e interfirieran en el derecho de los trabajadores a elegir sus representantes en la negociación y en especificar las reglas a las que la junta debía someterse. No era preceptivo llegar a ningún acuerdo; si no se producía éste, podía tener lugar una huelga. Si se alcanzaba el acuerdo, se debía poner por escrito si cualquiera de las dos partes así lo requiriese. Esta junta podía dirigir y supervisar elecciones para determinar en casos individuales el agente negociador adecuado en una empresa, y el elegido por la mayoría de los empleados como apropiado era el representante exclusivo de todos. También recopilaba una lista de prácticas ilegales como despedir a un trabajador sindicado u obligarle a que perteneciese a un sindicato determinado.

La jurisdicción de la junta se refería sólo a los patronos que llevasen a cabo comercio nacional o interestatal ${ }^{63}$. Si había pruebas de violación

63 Charles O. Gregory \& Harold A. Katz, op. cit., pág. 250. 
de la ley, de prácticas laborales injustas, la junta emprendía una acción legal, llevándose a los patronos ante los tribunales, ya que la junta no podía hacer cumplir sus órdenes. En teoría, los poderes de la junta eran extensos en teoría, al poder dictar fallos contra los patronos, pero no en la práctica, pues sólo oían quejas sin realmente mediar en las disputas laborales.

Con respecto a la sede principal de la junta de relaciones laborales, la ley determina que estuviese ubicada en Washington, aunque podía tener lugar en cualquier otro sitio.

Un aspecto importante de la junta residía en su autoridad para elaborar, concertar o rescindir reglas y reglamentos necesarios para llevar a cabo las disposiciones de esta ley. Estas se hacían efectivas al publicarse en la manera que prescriba la junta. Al final de cada año fiscal, la junta debía escribir un informe dirigido a las Cámaras y al Presidente, detallando los casos atendidos y decisiones tomadas.

La patronal intentó atacar la autoridad de la junta, sobre todo, en los dos primeros años de su funcionamiento. En 1937, el apoyo de la ley por el Tribunal Supremo permitió fortalecer la aplicación de la ley y la actuación de la junta.

\section{BALANCE HISTORIOGRÁFICO}

Se considera que la NLRA es la ley más significativa de 1935, al otorgar una nueva categoría a los obreros sindicados al garantizar el Gobierno el derecho a la sindicación y a la negociación colectiva. Incluso hay quienes opinan que tal vez sea la ley más importante aprobada en los años treinta.

Generalmente, la crítica considera que la ley nacional de relaciones laborales constituye un hito legislativo de la legislación del New Deal ${ }^{64}$. Se ha llegado a afirmar que es la medida más avanzada de la legislación laboral

64 Robert S. MAC Elvaine, op. cit., pág. 258; William E. LeUChTEnBuRG, op. cit., pág. 151; U.S. Department of Labor. Brief History of the American Labor Movement. Washington: U.S. Government Printing Office, 1976, pág. 22; Michaei GOLDFIELD, «Explaining New Deal Policy». American Political Science Review 84/4 (Dec. 1990), págs. 1299-1315, pág. 1309; Paul K. Edwards, op. cit., pág. 163; Detlef JunkeR, Franklin. D. Roosevelt, Macht und Vision: President in Krisenzeiten. Frankfurt: Muster-Schmidt, 1979, pág. 8; Walter GaLENSON y Robert S. SMITH, «Estados Unidos», En: John T. Dunlop y Waiter GalKenson (comp.), El trabajo en el siglo $x x$. Madrid: Ministerio de Trabajo y Seguridad Social, 1985, pág. 55. 
del New Deal ${ }^{65}$. Se la ha descrito como una norma «radical» y «una de las más drásticas innovaciones legislativas de la década" ${ }^{66}$. Esto se debe a que la National Labor Relations Act, junto con el artículo 7a) de la NIRA, allanaron el camino para conseguir avances en el mundo laboral y contribuyeron a cambiar la situación de dominio del poder de los empresarios. La NLRA dio un importante impulso al movimiento obrero y trató de alejar al patrono de los asuntos sindicales, prohibiéndole que presionase a los trabajadores para que no se afiliasen a sindicatos o se inmiscuyeran en escoger qué sindicato debían elegir. Debido a esto, la ley encontró una fuerte oposición entre los empresarios y sus organizaciones, que al principio, habían apoyado la NIRA. Los patronos se resistieron a respetar la ley, pese a las garantías del Gobierno, por lo que se produjeron huelgas, ya que muchos patronos hacieron caso omiso de la ley ${ }^{67}$. Los patronos podían violar el artículo ocho e interferir en una organización laboral y a la junta le sería difícil probarlo. De esto se deduce que la letra de la ley es un poco ambigua.

Esta medida logró que el gobierno respaldase la negociación colectiva y obligó a los patronos a aceptar pacíficamente la sindicación de los trabajadores. De todos modos, la aceptación de la ley tuvo lugar, sobre todo, durante la Segunda Guerra Mundial, porque las circunstancias forzaron a que se cree un ambiente de mayor cooperación ${ }^{68}$.

Según el historiador Melvyn Dubofsky, «la ley Wagner legitimaba plenamente el derecho de los obreros a organizarse y otorgaba un New Deal para el sindicalismo» ${ }^{69}$. Para James Mac Gregor Burns, la NLRA es la «legislación más radical aprobada durante el New Deal, en el sentido de que alteraba fundamentalmente la política de la nación al dar posesión de un sólido poder político y económico al obrerismo organizado" ${ }^{70}$. Incluso se la considera "revolucionaria». Como subraya Carl Degler, en la ley Wagner pueden verse "innovación y revolución en las actitudes del gobierno respecto al sindicalismo" ${ }^{71}$. Según Kenneth $\mathrm{S}$. Davis, la NLRA es

\footnotetext{
65 Howard ZinN, "The Conservative New Deal. New Deal Thought». En: Graham, OTIS L., Jr. (ed.). The New Deal. The Critical Issues. Boston: Little, Brown and Company, 1971, págs. 132-146, pág. 137.

66 William E. LeuchtenbuRG, op. cit., pág. 151.

Foster RHEA DULLES, op. cit., pág. 276.

68 Geeorge H. HILDEBRAND, «Labor: the Conservative New Deal. The Economic Effects of Unionism». En: Graham, OtIs L., Jr. (ed.). The New Deal. The Critical Issues. Boston: Little, Brown and Company, 1971, págs. 28-32, pág. 29.

69 Melvyn DuBOFSKY, op. cit., pág. 8.

70 James Mac Gregor BuRns, op. cit., pág. 218.

71 Carl N. Degler. Out of Our Past: the Force that Shaped America. N.Y.: Harper (1959), 1984, pág. 433.
} 
una de las pocas medidas del New Deal que realmente «diferenció la estructura de poder político-económico de América» ${ }^{72}$. Otros autores, en cambio, parecen disminuir la importancia de la ley al subrayar que la $N L R A$ es un mecanismo del programa antidepresión del New Deal ${ }^{73}$.

El derecho de los trabajadores a organizarse es esencial en una sociedad democrática. Además, se trata de conseguir que los trabajadores se contenten dentro del sistema capitalista. Por ello, esta ley reformista junto con otras iniciativas del New Deal contribuyó a ofrecer una «visión de una democracia industrial progresista» ${ }^{74}$. Quizás «los mayores avances en la organización autónoma de los trabajadores americanos tienen lugar entre 1932 y 1937, después de que la ley de requerimiento es derribada por la ley Norris-La Guardia (1932), pero antes de la decisión National Labor Relations Board versus Jones and Laughlin Steel Corporation en 1937, que validaba el papel de las Cámaras laborales de la ley Wagner» 75 . En cuanto a los trabajadores, Michael Goldfield argumenta que hay que tener en cuenta el papel que jugó la rebelión y la organización obrera en la aprobación y forma final de la $N L R A^{76}$.

Es una ley «preparada para fortalecer la posición negociadora de los trabajadores y consecuentemente su capacidad para obtener una mayor participación en el ingreso nacional» 77.

Con esta ley Roosevelt, pese a sus reticencias iniciales, consiguió un mayor apoyo de los sindicatos ${ }^{78}$. Irving Berstein resume las consecuencias del compromiso del Gobierno federal a apoyar la regulación de la negociación colectiva de este modo: 1.- crecimiento del número de afiliados a los sindicatos; 2.- reducción paulatina de la discriminación patronal hacia los trabajadores sindicados; 3.- disminución del número de huelgas emprendidas en defensa del derecho a sindicarse; 4.- la ley se convierte en una medida de seguridad para evitar la atracción de los trabajadores por el marxismo y el comunismo; 5.- fortalecimiento de la democracia industrial al elegir los obreros a sus representantes; 6.- surge un gran número de abogados defensores de la negociación colectiva; 7.- el intervencionismo federal dio

\footnotetext{
72 Kenneth S. Davis, op. cit., pág. 529.

73 Charles O. Gregory y Harold A. KaTZ, op. cit., pág. 225.

74 Leon FINk, In Search of the Working Class: Essays in American Labor History and Political Culture. Urbana/Chicago: University of lllinois Press, 1994, pág. 159.

75 Ibidem, pág. 162.

76 Michael GoldfiELD, «Workers Insurgency, Radical Organization and New Deal Labor Legislation". American Political Science Review, 83 (Dec. 1989), págs. 1257-1282, pág. 1257.

77 Foster RHEA DuLLES, op. cit., pág. 274.

78 Charles O. Gregory y Harold A. Katz, op. cit., pág. 225.
} 
una ventaja al $C I O$ en su lucha contra la $A F L$. Por último, la ley Wagner se consolidó permanente, concluyendo así la etapa de neutralidad ${ }^{79}$.

En definitiva, la ley Wagner es una ley clave del New Deal. Ahora bien, mientras que el título de esta ley laboral, National Labor Relations Act, nos incita a pensar en un ámbito extenso de regulación de las relaciones entre patronos y trabajadores, en realidad ésta se limitó a proteger y garantizar la libertad de sindicarse, el proceso de la negociación colectiva y el derecho a la huelga. Es decir, no se incluyeron aspectos, por ejemplo, como salario mínimo, seguro de paro, vacaciones o seguridad en el trabajo. A pesar de todo, debemos señalar que la medida tuvo un claro fin práctico, pues se consideraba que privar al trabajador del derecho a organizarse era causa de huelgas que perjudicaban a la industria y el comercio.

Por último, cabe destacar que la ley Wagner encontró una fuerte oposición y no fue respetada mayoritariamente hasta la legitimación legal del tribunal Supremo en 1937. La aceptación de la ley tuvo lugar, durante la guerra mundial, porque las circustancias forzaban a que se crease un ambiente de más cooperatividad ${ }^{80}$. La ley puso los cimientos de la legislación laboral que ha seguido vigente en la actualidad, aunque se vió modificada por la promulgación de otras leyes. Así, parte de sus disposiciones se pudieron encontrar posteriormente en la Taft-Hartley Act de 1947.

\section{VISIÓN DE LA LEY WAGNER EN LA PRENSA ESPAÑOLA}

Mientras que la ley Wagner suscitó una gran expectación en la prensa estadounidense, ocupando las primeras páginas de los periódicos en marzo, abril y julio de 1935, en España no se dio tanto eco a esta ley, habiendo muy pocas noticias sobre ella. La mayoría de los diarios españoles estudiados no aludieron a la ley y aquellos que lo hicieron apenas si la prestaron atención. Esto nos lleva a plantearnos si ello se podía deber a motivos ideológicos de quienes ocupaban el poder en esas fechas en la Segunda República española y de la oposición, y a tratar de ver qué intereses tenían para no desear propagar la ley citada. ¿Fue una omisión táctica?

Tras la derrota electoral de la izquierda en 1933 se sucedieron las multas y suspensiones, sobre todo, a raíz de la fallida revolución de oc-

\footnotetext{
79 Irving BERSTEIN, “Labor: the Revolutionary New Deal. The End of the Turbulent Years". En: Graham, OtIs L., Jr. (ed.), The New Deal. The Critical Issues. Boston: Little, Brown and Company, 1971, págs. 18-27, págs. 24-26.

so Geeorge H. Hildebrand, op. cit., pág. 29.
} 
tubre de 1934, momento en el que tuvieron lugar la suspensión de muchos periódicos republicanos de izquierda, de prensa comunista, socialista y libertaria y de la vinculada al Esquerra Republicana de Catalunya. En el período de aprobación de la ley NLRA en 1935, entre los diarios analizados en este ensayo que sufren suspensión, están: CNT, El Socialista y Mundo Obrero ${ }^{81}$. Por lo tanto, el sector de la prensa obrera que, seguramente, hubiese hecho bastante alusión a esta ley, quedó silenciado.

Las noticias sobre la ley de relaciones laborales estadounidense de 1935 fueron muy escasas en la prensa conservadora, tal vez porque se pretendía que la incidencia fuese mínima. No se debe olvidar que esta ley fue aprobada durante la etapa del bienio conservador español, que pretendía ser un «sistema político destinado a mantener las mismas relaciones de poder social y económico vigentes en la España monárquica» ${ }^{82}$. Por el contrario, la ley Wagner era una medida reformista que trataba de impulsar el sindicalismo y la negociación colectiva, algo que, seguramente, se intentaba evitar en aquellos momentos en España.

Anteriormente, en la España del bienio reformista surgió una ley similar en algunos puntos a la ley Wagner, sobre todo, al pretender, como aquélla, legitimar la negociación colectiva para mejorar las relaciones entre obreros y patronos. La «Ley de Contratos de Trabajo», aprobada el 21 de noviembre de 1931, buscaba -entre otros fines- restringir las causas de despido y reconocer el derecho a la huelga. Un organismo fundamental eran los Jurados Mixtos profesionales creados el 27 de noviembre de 1931, que trataban de solucionar los conflictos entre obreros y patronos y vigilar los contratos y las condiciones laborales. Ahora bien, durante el bienio conservador, la derecha y la patronal consiguieron, mediante una reforma de la ley, limitar sus funciones a partir de agosto de 1935. Curiosamente, esta fecha coincidió aproximadamente con la de la aprobación de la ley Wagner, que tuvo lugar en el mes de julio.

La ley Wagner suponía un impulso de unas medidas legislativas que, de tener eco en España, perjudicarían los intereses del gobierno conservador. Por ello, o bien la prensa afecta al régimen omite del todo cualquier referencia a la ley estadounidense o bien la prensa tolerada la da

81 Suspensiones: Mundo Obrero. Del 6 de octubre de 1934 al 2 de enero de 1936. El Socialista. Del 6 de octubre de 1934 al 16 de diciembre de 1936. CNT. Cesó el 6 de octubre de 1934 tras haber sufrido ya una suspensión en 1933. Reaparició el 28 de octubre de 1936.

82 Marta BizcarRondo, Leviatán y el socialismo de Luis Araquistáin. Nendeln-Liechtenstein: Detlev Auvermann KG, 1974, pág. 10. 
muy poca publicidad, abordando el tema veladamente, ante el temor de una posible censura.

Comprobamos que la prensa española recogió pocas noticias y reflexiones sobre este nuevo intento de reforma. La mayoría de las noticias aparecieron publicadas en el diario independiente conservador La Vanguardia, que generalmente solía ofrecer información, limitándose a publicar unas cuantas noticias de agencia sobre esta ley. No dedicó al tema editoriales y ni artículos que la resaltasen. Este diario de Barcelona, que generalmente subrayaba que existía un marcado carácter social en las leyes reformistas del segundo New Deal, entre las que destacó la ley de seguridad social y la ley Wagner, se limitó a incluir a la ley Wagner como una medida social más dentro de las iniciadas en 1935, y señaló que no era algo nuevo en Europa:

«Roosevelt ha emprendido la realización de un vasto programa de reconstrucción del sistema social de los Estados Unidos así como el impulso a la aplicación práctica del programa contra la depresión. Las reformas básicas decretadas por el Congreso incluyen medidas de seguridad social destinadas a socorrer a la ancianidad y a los sin trabajo y a la legalización del derecho de los Sindicatos de trabajo a escoger representantes para la discusión colectiva con los patronos de las condiciones de trabajo. Medidas similares han sido establecidas ya en muchos países europeos, pero en Estados Unidos están consideradas como un nuevo modo de responsabilidad colectiva» ${ }^{83}$.

En estos casos, el rotativo transmitía la idea al lector de que los Estados Unidos no era un modelo para Europa, y además, el diario no reconocía a su vez ninguna influencia europea. Este enfoque era una manera de quitar importancia al ejemplo estadounidense y de afirmar la independencia europea. Anteriormente, este periódico había publicado que el proyecto de ley Wagner garantizaba al trabajador el derecho a la negociación colectiva, prohibiendo el funcionamiento de los sindicatos de las empresas, y aseveró que se trataba de un proyecto de gran alcance, que establece una junta independiente del Ministerio de Trabajo. Parece que se intentó que la ley pasase desapercibida. La ley se firma el 5 de julio de 1935. En lugar de mencionarlo en el titular, esto se dijo dentro de la noticia y el titular seguía hablando de "proyecto", cuando ya era una ley. Además, se cuestionó su legalidad, al recogerse el dato de

83 «El carácter social de la legislatura clausurada. Las medidas de orden internacional». La Vanguardia. Barcelona, X 28-8-1935, pág. 21. 
que pudiera ser declarada inconstitucional, como ocurrió con los códigos del NRA ${ }^{84}$.

Por su parte, los diarios de derecha Informaciones y El Debate se ocuparon de hacer alusión a la firma de la ley con un titular idéntico sin dedicar un gran artículo al tema. Esto pudo llegar a desconcertar al lector que no había recibido información previa sobre la ley en cuestión ${ }^{85}$. En otra ocasión, aparece, en unas líneas de una noticia de agencia sobre la National Recovery Administration (NRA), una mención del apoyo de Roosevelt al decreto de ley Wagner como un «gesto a favor de los sindicatos obreros» ${ }^{86}$. O sea, la prensa española conservadora minimiza u oculta los aspectos ideológicos de búsqueda de mayor justicia social y defensa de los derechos democráticos obreros. Sobre los objetivos de la ley, los diarios conservadores publican que surge para evitar huelgas y conflictos ${ }^{87}$. Es decir, hacen hincapié en la idea de que en los Estados Unidos se comparte su anhelo de paz social.

Los diarios de izquierda, La Libertad y El Liberal de Madrid aluden al otro objetivo de la ley Wagner: la regulación de las relaciones entre patronos y obreros. Una de las noticias es incluso sobre un tema distinto, abordando la ley someramente y escondidas ${ }^{88}$. Seguramente, la prensa de izquierda no celebraba los planteamientos democráticos de la ley, por temor a ser suspendida.

El Socialista es el diario que más resaltó los planteamientos e intención de reformas sindicales. Se ocupó del proyecto de ley Wagner de 1934, lamentándose al ver que no prosperaba, y criticó que Roosevelt se rindiese a la patronal: «Roosevelt capitula ante los patronos. A Roosevelt se le concede el poder designar una o varias juntas conciliadoras, pero la ley Wagner se pospone" ${ }^{89}$. En 1935 no pudo hacer mención de la ley, porque no se publicó este diario hasta diciembre, ya que sufrió una suspensión de catorce meses a raíz de los sucesos de octubre de 1934.

\footnotetext{
84 «El proyecto de ley de organización obrera». La Vanguardia. Barcelona, S 6-7-1935, pág. 26.

85 «El presidente Roosevelt ha firmado la ley». El Debate. Madrid, S 6-7-1935, pág. 7; «El presidente Roosevelt ha firmado !a ley». Informaciones. Madrid, S 6-7-1935, pág. 7.

86 «La nueva organización». La Vanguardia. Barcelona, J 6-6-1935, pág. 29.

87 «Los conflictos de trabajo». La Vanguardia. Barcelona, J 20-6-1935, pág. 31; «Los pleitos sociales». El Debate. Madrid, V 17-5-१935, pág. 4; «El Gobierno yanqui preocupado por la extensión de los conflictos sociales.- Los conflictos sociales». El Debate. Madrid, M 18 de junio de 1935, primera página.

${ }_{88}$ «Roosevelt reclama un impuesto sobre los ricos para el pago de los gastos de seguros sociales". La Libertad. Madrid, M 25-6-1935, pág. 12; “Obreros y patronos norteamericanos.- El presidente Roosevelt ha firmado la ley Wagner». El Liberal. Madrid, S 6-7-1935, pág. 7.

89 «Roosevelt capitula ante los patronos.- Queda abrogada la ley Wagner, que protegía el derecho sindical de los obreros". El Socialista. Madrid, 17-6-1934, última página.
} 


\section{CONCLUSIÓN}

La National Labor Relations Act puede ser considerada la más avanzada de las leyes laborales del New Deal, al allanar el camino para conseguir avances en el mundo laboral y contribuir a cambiar la situación de dominio del poder de los empresarios.

El cambio de las relaciones entre el capital y el trabajo vino determinado por las luchas y conflictos sociales, por el intervencionismo gubernamental y las actitudes liberales dentro del Gobierno de Roosevelt de personas que impulsan una legislación reformista. Se debe destacar el papel decisivo que ejerció el senador liberal Robert $F$. Wagner en la consecución del derecho de los obreros a la sindicación mediante su empeño en que se sancionara la NLRA. El Gobierno se mantuvo ajeno a la aprobación de la medida. No obstante, el Estado estadounidense asumió un papel protector en relación a la sindicación y negociación colectiva en la era Roosevelt, imponiendo a los empresarios tolerancia y reconocimiento, lo cual generó una importante recuperación sindical. Esto nos lleva a plantearnos hasta qué punto debe el Estado intervenir en las relaciones laborales y si es importante tener una regulación laboral estatal y si es o no mejor que exista una política nacional para proteger los derechos de los trabajadores a que sólo las empresas privadas regulen todo, y tengan una libertad alssoluta en cuanto a despidos y condiciones laborales.

Respecto a la visión de la ley NLRA en la prensa española, se observa se trató de silenciar la existencia de esta ley que supuso un importante impulso para el movimiento obrero estadounidense. Durante el bienio conservador de la Segunda República, el sistema político comprimió aspiraciones por medio de una restricción a la vida asociativa, puesto que los sindicatos promueven, canalizan y exponen pretensiones obreras, lo cual explica, en parte, que la prensa conservadora de derecha omitiera toda referencia clara a este logro legislativo en ese período mencionado y que el gobierno vigilase, a su vez, para que el resto de la prensa no lo propagase. Se evitaba hablar de una necesidad de reforma de la legislación laboral, temiendo que esto pudiese ejercer una influencia en la opinión pública que llevase a plantear ciertas reformas.

En conclusión, el análisis de la ley nacional de relaciones laborales muestra que esta medida no fue sólo importante por su repercusión en el panorama social estadounidense, en el crecimiento de los sindicatos y en la estructura laboral, desde su promulgación hasta la actualidad, sino que no pasó desapercibida para determinados grupos de poder españoles que, seguramente, temiendo una posible influencia en el panorama social español, trataron de silenciarla bajo una mirada vigilante, a juzgar por escasísima información sobre la ley y la reacción partidista que se ofrece de la misma. 